Research Article

\title{
Longitudinal Deformation Model and Parameter Analysis of Canal Lining under Nonuniform Frost Heave
}

\author{
Pengfei He $\mathbb{D}^{1},{ }^{1}$ Jianhua Dong $\mathbb{D},^{2,3}$ Xin Ren, ${ }^{2,3}$ and Xiaolei Wu $\mathbb{C}^{2,3}$ \\ ${ }^{1}$ School of Science, Lanzhou University of Technology, Lanzhou 730050, China \\ ${ }^{2}$ School of Civil Engineering, Lanzhou University of Technology, Lanzhou 730050, China \\ ${ }^{3}$ Key Laboratory of Disaster Prevention and Mitigation in Civil Engineering of Gansu Province, \\ Lanzhou University of Technology, Lanzhou 730050, China \\ Correspondence should be addressed to Jianhua Dong; djhua512@163.com
}

Received 5 January 2021; Revised 19 February 2021; Accepted 5 May 2021; Published 20 May 2021

Academic Editor: Ying-hao Huang

Copyright (C) 2021 Pengfei He et al. This is an open access article distributed under the Creative Commons Attribution License, which permits unrestricted use, distribution, and reproduction in any medium, provided the original work is properly cited.

\begin{abstract}
Due to the unique hydrothermal environments, the frost heave failure of the concrete lining of water conveyance canals in cold regions is still frequent. The deformation of lining after frost heaving and the stress distribution calculated by the mechanical model can be the reference for the lining design. However, previous research mainly focused on the mechanical model of the cross-section while having little attention for the longitudinal nonuniform frost heave damage. In this study, a mechanical model of the bottom lining under the nonuniform frost heave deformation is built based on the Euler-Bernoulli beam and the Pasternak foundation model, and the analytical solution of the model is obtained. The internal stress of the lining is analyzed during the changes of subgrade coefficient, shear rigidity, transition section length, and frost heave amount inside the model. Also, the calculation process is proved to be correct. The result shows that dangerous cross-sections are at the start and the end of the transition sections. The maximum normal stress and the tangential stress increase when the subgrade coefficient and the frost heave amount increase and the shear modulus and transition section length decrease. The frost heave amount in the frozen ground subgrade increases constantly, while the temperature decreases, but at the same time, the shear rigidity of the subgrade increases with it. The former increases the stress of lining, and the latter decreases it. Therefore, during the frost heaving process, the internal force of lining is coupled with these two elements. By analyzing a water conveyance canal lining under the nonuniform frost heave in the Xinjiang Tarim irrigation district, the maximum normal stress of the dangerous lining cross-section is greater than its tensile strength when the transition section length smaller than $7 \mathrm{~m}$ at the frost heave amount is $0.031 \mathrm{~m}$.
\end{abstract}

\section{Introduction}

The area where the surface temperature is continuously lower than $0^{\circ} \mathrm{C}$ throughout the year or the coldest season is called the frozen ground, and about 50\% of the land area on the earth belongs to the frozen ground [1]. In the process of soil freezing, the volume of pore water after freezing will increase by $9 \%$ to cause frost heave. Simultaneously, the water in the unfrozen soil migrates to the freezing edge due to the temperature gradient and form segregated ice, which will also cause frost heave [2]. Therefore, engineering structures in the cold regions often suffer from the effects of frost heave damage.

In China, about $52 \%$ of the land is in the frozen ground, such as the Xinjiang Uygur Autonomous Region. It is in the arid area of the middle-temperature zone and cold and arid in winter, and a large scale of the area is covered with seasonally frozen soil [3]. The days when the maximum temperature is below $0^{\circ} \mathrm{C}$ can be up to 130 days, and the temperature difference between day and night is great. Due to scarce precipitation and extremely uneven distribution of the water resources, many reservoirs and long-distance conveyance canals have been built to meet factory and mine production, urban life, and farmland irrigation. More than $90 \%$ of farmland irrigation water depends on the supply of conveyance canals $[4,5]$. Therefore, the secure operation of these reservoirs and long-distance conveyance canals is critical to the production and life of the people in these regions. 
To reduce leakage, the water conveyance canals are usually paved with concrete lining on the slope and bottom of the canals, which significantly improves the water utilization efficiency of the canal system $[6,7]$. However, in the years of the operation process, due to repeated freezing and thawing, hydraulic scouring, and other external loads effects, it is inevitable that the lining and joints will rupture and cause leakage. Leakage during the water delivery period can cause loss of foundation soil, the collapse of canal slopes, and instability of lining. During the water outage period in winter, the water content of the base soil is generally higher due to the previous leakage, and the subzero temperature conditions and the higher fine-grained soil content in the base soil of the canal make the canal foundation have sufficient conditions for frost heave to occur. Also, the temperature in the seasonally frozen soil area drops slowly, the freezing rate is relatively low, and the water has sufficient time to migrate to the soil near the lining, which causes a significant frost heave effect [8]. The frost heave of the canal foundation soil in some areas can reach $15 \mathrm{~cm}$ [9]. Due to the mutual restraint between the slope lining and the floor lining and the upper berm, the frost heave deformation cannot be released, the resulting frost heave force causes the lining to break in extreme cases, further aggravating the leakage of the canal during the water delivery period. This repeated process leads the water conveyance canal to be in a vicious circulation of "frost heave, lining damage, leakage, and more severe frost heave."

Many water conservancy projects were built in 1950s and 1960s and were limited by the low construction technology level and conditions at that time; most of the canal foundations used local soil materials containing a large number of fine particles during the construction process and then laying concrete lining slabs in the reservoir and large canal in order to prevent leakage. At the same time, small branch canals were rarely lined. Due to insufficient understanding of the frost heaving problem at that time and the long-term hydraulic erosion and repeated freeze-thaw effects in the later operation process, these projects are still frequently having damage issues, one of which is the frost heaving failure on the lining plate of the concrete lining canal. For example, Xiao et al. [10] found a serious frost heaving issue in the water conveyance canals lining in the Tarim irrigation district in Xinjiang, especially rigid lining canals. Qin et al. [4] found that the concrete slabs of reservoirs in Xinjiang were prone to cracks near the water level in winter under the effect of frost heave force and ice pressure. Sun et al. [11] found that there were also serious issues of freezing damage to lining panels in reservoirs and water conveyance canals in Heilongjiang Province. Tian's et al. research [12] shows that the primary cause of the horizontal damage on the concrete lining of the drainage canal of the Qinghai-Tibet Railway subgrade is the horizontal frost heave force, and the main cause of the longitudinal damage is the uneven frost heave displacement. In some other cold region's water conservancy projects, there are also lining damage caused by the frost heave effect [13-15].

To avoid the abovementioned problems, engineers used soil replacement, laying thermal insulation, and other measures to reduce frost heave damage effectively $[7,16]$. However, many early built canals could not be rebuilt, and the problem of frost damage still occurs frequently. Therefore, many scholars have conducted numerous theoretical calculations and experimental studies on the frost heave failure mechanism of the concrete lining in frozen soil areas, which provide scientific references for the repair and treatment of canals with severe frost damage. Li et al. [17] and $\mathrm{Li}$ et al. [18] conducted a numerical simulation of the frost heave failure mechanism of the lining canals. However, there were many influencing factors to be considered in the simulation process, and the calculation process was complicated and cumbersome, which was very inconvenient in the application of engineering practice. Therefore, it is still necessary to analyze the force characteristics and failure mechanism of the lining under frost heave effects through simple and convenient theoretical calculation methods. Wang [19] investigated the lining damage of the canals in the cold regions and found that frost heave deformation was the main cause of the lining fracture. By a mechanical model, the lining slab was simplified into a simply supported beam. The force analysis of the concrete lining with different crosssection shapes under the simultaneous actions of frost heaving force, and freezing force was carried out using the material mechanics method. The calculation results were consistent with the field test. The failure position of the lining slope and the maximum stress cross-section were at $1 /$ 3 from the bottom of the canal, and the maximum normal stress of the bottom lining was in the middle position. Since then, many scholars have used this model to analyze the force and deformation characteristics of the lining under frost heave in different conditions [20, 21]. However, the above method did not consider the deformation coordinative of the lining and the base soil deformation during frost heave. To overcome this defect, researchers calculated the force characteristics of the lining under frost heave effects based on the Winkler elastic foundation beam theory and constructed a judgment criterion for lining frost heave failure. The calculation results were consistent with the onsite monitoring data $[10,22]$.

However, the abovementioned models are based on the deformation characteristics of the cross-section of the canals and studying the failure characteristics of the lining crosssections. Due to differences in the geological conditions of the water conveyance canals subgrade in the longitudinal direction of the canal line, there will inevitably be uneven frost heave deformation along the longitudinal direction, and lining damage will also be caused under extreme conditions. There are few reports on the model and analysis of the longitudinal deformation and force characteristics of the lining under frost heave effects. This study takes the longitudinal deformation of the water conveyance canal lining in the cold region under the action of nonuniform frost heave as the research object, based on the Pasternak model to establish the mechanical model of the bottom lining and calculates the key parameters in the model. Combined with a typical engineering case, the longitudinal deformation and stress characteristics of the bottom lining are calculated and analyzed. 


\section{Model and Methods}

Due to the differences in geology and construction conditions and the effects of long-term leakage and freeze-thaw cycles, the amount of frost heave at different locations in the longitudinal direction of the lining will be different, leading to the bending deformation of the lining. Because the slope lining is laid inclined vertically, the bending stiffness is relatively larger in the vertical direction, and it is not prone to cause damage in the longitudinal direction. The bottom lining is laid horizontally, and the bending stiffness is small in the vertical direction. Under the effect of nonuniform frost heave deformation, the cross-sectional stress is prone to be too large and leading to damage. Therefore, a mechanical model is established for the bottom lining. Figure 1 is a schematic diagram of the nonuniform frost heave deformation of the bottom lining. The $x$-direction is the longitudinal direction of the canal (canal line direction), and the $y$-direction is the vertical direction. Assuming that the AO section is the no-frost heave section, the $\mathrm{BC}$ section is a frost heave section, and its maximum frost heave deformation amount is $\Delta$; the $\mathrm{OB}$ section is a frost heave transition section with a length of $l$. The coordinate system is established as shown in Figure 1; then, the deformation of the entire lining in the $y$-direction can be expressed by formula (1).

$$
y_{0}= \begin{cases}0, & x<0, \\ \frac{\Delta}{l} x, & l>x>0, \\ \Delta, & x>l .\end{cases}
$$

2.1. Basic Assumptions and Conventions. Due to the complex physical-mechanical properties of frozen soil and various external factors, the stress and strain of frozen soil are showing obvious characteristics of nonlinear, irreversible, and time-varying [22-24]. It must be a tedious work to solve the interaction between frozen soil and structure by considering all the influencing factors. To obtain meaningful data for practical engineering problems, combining the existing research and engineering practice experience, the following assumptions and agreements are made [10, 19, 22].

(1) Only consider the vertical deformation of the bottom lining caused by nonuniform frost heave in the longitudinal direction, ignore the influence of the axial force of the bottom lining, and the friction resistance between the bottom lining and the foundation soil on the longitudinal deformation, and simplify the mechanical analysis model as a plane strain problem.

(2) During the frost heave, the deformation of the lining and the foundation soil is in a coordinated and balanced state, and the process of failure of the lining is considered a quasistatic process. The stress analysis only considers the limit state at the maximum frost heave amount.

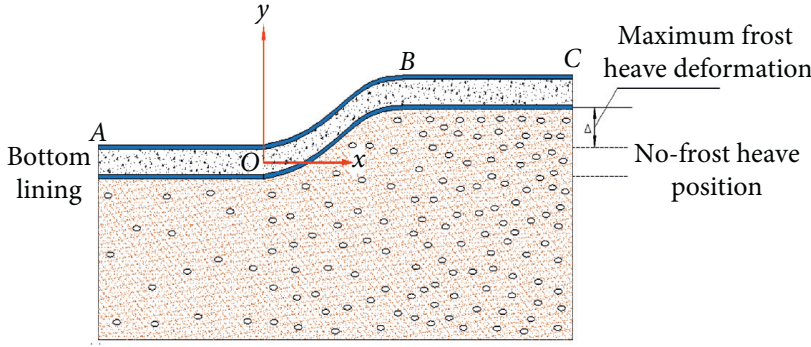

FIgURE 1: Schematic diagram of nonuniform frost heave deformation of bottom lining.

(3) The canal foundation is regarded as the elastic foundation obeying the Pasternak model, and the lining is regarded as the Euler-Bernoulli beam. The final deformation of the bottom lining is the deformation amount under restrictions such as slope lining, lining's weight, and so on.

(4) The deformation of the foundation soil only considers the range of frost penetration

2.2. Frozen Soil-Lining Interaction Model. The elastic foundation beam model can better reflect the interaction between the structure and soil. The Winkler model assumes that the surface displacement at each point of the soil medium is proportional to the stress acting at that point [25]. However, the mechanical activation behavior of the soil in the model is completely discontinuous, and the soil is completely irrelevant to the stresses or displacements of other points, even the nearest ones on the interface of the foundation, which is contrary to the actual mechanical activation behavior of the soil. To overcome the abovementioned defects, the twoparameter model introduces mutual mechanical action between the spring elements of the Winkler model to eliminate its discontinuous behavior [26]. Among many two-parameter models, the soil behavior model proposed by Pasternak assumes that there is a shearing interaction between the spring elements, and this shearing interaction is achieved by connecting the spring elements to a layer of vertical elements which can only produce lateral shearing deformation but not compressible [27]. During the freezing process of the soil mass, the elastic modulus and shear strength increase with the decrease of temperature [28]. Moreover, during the deformation of the superstructure, the foundation must bear a certain amount of shearing force. Therefore, the Pasternak model corresponds with the actual engineering situation of the mechanical properties of the frozen soil than the Winkler model.

Consider the bottom lining as an Euler-Bernoulli infinite long beam, which adopts the Pasternak model to the frozen ground, and the differential equation of displacement under plane strain conditions is $[26,27]$

$$
E I y^{(4)}-G b y^{(2)}+k b y=q_{0},
$$

where $b$ is the effective width, $G$ is the shear stiffness of the elastic layer, $k$ is the foundation coefficient, $E$ is the elastic 
modulus of the beam, $I$ is the moment of inertia of the beam, and $q_{0}$ is the normal load acting on the beam. According to assumption (6), the normal load acting on the lining is balanced with part of the foundation counterforce. Only the deformation of the lining caused by frost heave is considered. Therefore, equation (2) can be transformed into a homogeneous type for the solution.

Let $\quad \beta=\sqrt[4]{k b / 4 E I}, \quad \gamma=\sqrt{k / G}, \quad$ and $\quad \rho=(\beta / \gamma)^{2}=$ $G / \sqrt{k E I / b}$. Then, the homogeneous differential equation corresponding to equation (2) becomes

$$
y^{(4)}-4 \beta^{2} \rho y^{(2)}+4 \beta^{4} y=0 .
$$

2.3. Model Solution. The solutions of equation (3) can be divided into three cases, which are $\rho>1, \rho=1$, and $\rho<1$. The condition of $\rho<1$ satisfies most projects, which is also proved in the following parameter analysis and calculation of engineering examples [26]. Considering the boundary condition (1), the solution of the differential equation (3) can be expressed [28-30]. In the AO section, the frost heave deformation is 0 , and the solution of equation (3) is

$$
\begin{aligned}
y_{1}= & \left(A_{1} e^{-\varphi_{1} x}+A_{2} e^{\varphi_{1} x}\right) \cos \varphi_{2} x \\
& +\left(A_{3} e^{-\varphi_{1} x}+A_{4} e^{\varphi_{1} x}\right) \sin \varphi_{2} x .
\end{aligned}
$$

In the $\mathrm{BC}$ section, the frost heave deformation is $\Delta$, and the solution of equation (3) is

$$
\begin{aligned}
y_{3}= & \left(A_{1} e^{-\varphi_{1} x}+A_{2} e^{\varphi_{1} x}\right) \cos \varphi_{2} x \\
& +\left(A_{3} e^{-\varphi_{1} x}+A_{4} e^{\varphi_{1} x}\right) \sin \varphi_{2} x+\Delta .
\end{aligned}
$$

The OB section is the transition section, the frost heave amount is $(\Delta / l) x$, and the solution of equation (3) is

$$
\begin{aligned}
y_{2}= & \left(A_{5} e^{-\varphi_{1} x}+A_{6} e^{\varphi_{1} x}\right) \cos \varphi_{2} x \\
& +\left(A_{7} e^{-\varphi_{1} x}+A_{8} e^{\varphi_{1} x}\right) \sin \varphi_{2} x+\frac{\Delta}{l} x .
\end{aligned}
$$

The above three equations $(4 a)-(4 c)$ should meet the following boundary conditions:

When $x \longrightarrow \infty$, then $y_{3}=\Delta$

When $x \longrightarrow-\infty$, then $y_{1}=0$

Substituting the boundary conditions into equations (4a)-(4c), the following equation can be obtained.

$$
\begin{aligned}
y_{1}= & A_{2} e^{\varphi_{1} x} \cos \varphi_{2} x+A_{4} e^{\varphi_{1} x} \sin \varphi_{2} x, \\
y_{3}= & A_{1} e^{-\varphi_{1} x} \cos \varphi_{2} x+A_{3} e^{-\varphi_{1} x} \sin \varphi_{2} x+\Delta, \\
y_{2}= & \left(A_{5} e^{-\varphi_{1} x}+A_{6} e^{\varphi_{1} x}\right) \cos \varphi_{2} x \\
& +\left(A_{7} e^{-\varphi_{1} x}+A_{8} e^{\varphi_{1} x}\right) \sin \varphi_{2} x+\frac{\Delta}{l} x .
\end{aligned}
$$

There are still eight unknown coefficients in equations (5a)-(5c). Thus, the continuity conditions of the points $O$ and $B$ should also be satisfied.

$$
\begin{aligned}
& \text { When } x=0, y_{1}=y_{2}, y_{1}^{\prime}=y_{2}^{\prime}, y_{1}^{\prime \prime}=y_{2}^{\prime \prime}, y_{1}^{\prime \prime \prime}=y_{2}^{\prime \prime \prime} \\
& \text { When } x=l, y_{2}=y_{3}, y_{2}^{\prime}=y_{3}^{\prime}, y_{2}^{\prime \prime}=y_{3}^{\prime \prime}, y_{2}^{\prime \prime \prime}=y_{3}^{\prime \prime \prime}
\end{aligned}
$$

After substituting the above 8 continuity conditions into equations (5a) $-(5 \mathrm{c})$, simultaneously, the equations to obtain the equation coefficients $A_{1} \sim A_{8}$ are as follows:

$$
\begin{aligned}
& A_{1}=\frac{\left[\Delta e^{\varphi_{1} l}\left(3 \varphi_{1}^{2} \varphi_{2} e^{-\varphi_{1} l}-\varphi_{2}^{3} e^{-\varphi_{1} l}+\varphi_{1}^{3} \sin \varphi_{2} l+\varphi_{2}^{3} \cos \varphi_{2} l-3 \varphi_{1}^{2} \varphi_{2} \cos \varphi_{2} l-3 \varphi_{1} \varphi_{2}^{2} \sin \varphi_{2} l\right)\right]}{\left[4 l \varphi_{1} \varphi_{2}\left(\varphi_{1}^{2}+\varphi_{2}^{2}\right)\right]}, \\
& A_{2}=\frac{\left[\Delta e^{-\varphi_{1} l}\left(3 \varphi_{1}^{2} \varphi_{2} e^{\varphi_{1} l}-\varphi_{2}^{3} e^{\varphi_{1} l}-\varphi_{1}^{3} \sin \varphi_{2} l+\varphi_{2}^{3} \cos \varphi_{2} l-3 \varphi_{1}^{2} \varphi_{2} \cos \varphi_{2} l+3 \varphi_{1} \varphi_{2}^{2} \sin \varphi_{2} l\right)\right]}{\left[4 l \varphi_{1} \varphi_{2}\left(\varphi_{1}^{2}+\varphi_{2}^{2}\right)\right]}, \\
& A_{3}=\frac{\left[\Delta e^{\varphi_{1} l}\left(-3 \varphi_{1} \varphi_{2}^{2} e^{-\varphi_{1} l}+\varphi_{1}^{3} e^{-\varphi_{1} l}-\varphi_{1}^{3} \cos \varphi_{2} l+\varphi_{2}^{3} \sin \varphi_{2} l+3 \varphi_{1} \varphi_{2}^{2} \cos \varphi_{2} l-3 \varphi_{1}^{2} \varphi_{2} \sin \varphi_{2} l\right)\right]}{\left[4 l \varphi_{1} \varphi_{2}\left(\varphi_{1}^{2}+\varphi_{2}^{2}\right)\right]}, \\
& A_{4}=\frac{\left[\Delta e^{-\varphi_{1} l}\left(3 \varphi_{1} \varphi_{2}^{2} e^{\varphi_{1} l}-\varphi_{1}^{3} e^{\varphi_{1} l}+\varphi_{1}^{3} \cos \varphi_{2} l+\varphi_{2}^{3} \sin \varphi_{2} l-3 \varphi_{1} \varphi_{2}^{2} \cos \varphi_{2} l-3 \varphi_{1}^{2} \varphi_{2} \sin \varphi_{2} l\right)\right]}{\left[4 l \varphi_{2}\left(\varphi_{1}^{2}+\varphi_{2}^{2}\right)\right]}, \\
& A_{5}=\frac{\left[\Delta\left(3 \varphi_{1}^{2}-\varphi_{2}^{2}\right)\right]}{\left[4 l \varphi_{1}\left(\varphi_{1}^{2}+\varphi_{2}^{2}\right)\right]}, \\
& A_{6}=\frac{\left[\Delta e^{-\varphi_{1} l}\left(-\varphi_{1}^{3} \sin \varphi_{2} l+\varphi_{2}^{3} \cos \varphi_{2} l+3 \varphi_{1} \varphi_{2}^{2} \sin \varphi_{2} l-3 \varphi_{1}^{2} \varphi_{2} \cos \varphi_{2} l\right)\right]}{\left[4 l \varphi_{1} \varphi_{2}\left(\varphi_{1}^{2}+\varphi_{2}^{2}\right)\right]},
\end{aligned}
$$




$$
\begin{aligned}
& A_{7}=\frac{\left[\Delta\left(\varphi_{1}^{2}-3 \varphi_{2}^{2}\right)\right]}{\left[4 l \varphi_{2}\left(\varphi_{1}^{2}+\varphi_{2}^{2}\right)\right]}, \\
& A_{8}=\frac{\left[\Delta e^{-\varphi_{1} l}\left(\varphi_{1}^{3} \cos \varphi_{2} l+\varphi_{2}^{3} \sin \varphi_{2} l-3 \varphi_{1} \varphi_{2}^{2} \cos \varphi_{2} l-3 \varphi_{1}^{2} \varphi_{2} \sin \varphi_{2} l\right)\right]}{\left[4 l \varphi_{1} \varphi_{2}\left(\varphi_{1}^{2}+\varphi_{2}^{2}\right)\right]} . \\
& k^{\prime}=\frac{(1-\mu) E_{f}}{(1+\mu)(1-2 \mu) H} .
\end{aligned}
$$

(3) of the bottom lining, the rotation angle $(\theta)$, bending moment $(M)$, and shearing force $(Q)$ of the lining can be calculated.

$$
\begin{aligned}
\theta & =y^{\prime}, \\
M & =-E I y^{\prime \prime}, \\
Q & =Q_{c}+Q_{s}=-E I y^{\prime \prime \prime}+G b y^{\prime} .
\end{aligned}
$$

In equation (9), the first term of shear force is the shearing force of the lining slab, and the second one is the shearing force of the elastic foundation.

\subsection{Model Parameters}

2.4.1. Foundation Coefficient $k$. Generally, the foundation coefficients can be obtained through experiments or calculating the mechanical parameters of the foundation soil [25]. However, the interaction between the frozen soil ground and the lining is that the displacement of the surface of the foundation occurs with the frost heave. However, due to the external constraints, part of the frost heave displacement is restricted, resulting in frost heave force on the structures. Therefore, the relationship between frost heave force and frost heave displacement can be regarded as the relationship between the pressure on the foundation surface and the displacement at that point. Xiao et al. [10] calculated the lateral deformation of the canal lining and obtained the foundation coefficient considering the interaction process between the lining and the foundation during the frost heave deformation process which can be expressed as

$$
k=\frac{E_{f}}{H_{f}},
$$

where $E_{f}$ is the elastic modulus of frozen soil, and $H_{f}$ is the depth of frozen penetration.

This is the same as the foundation coefficient calculation method of Kanie et al. [28] in calculating the nonuniform frost heave of oil pipelines in the frozen soil layer.

In the usual melted soil foundation, Tanahashi [26] simplified Vesic's formula and recommended to calculate the foundation coefficient under the condition of one-dimensional plane strain by the following formula:
When taking the Poisson ratio $\mu=0.2,0.25,0.3$, and 0.35 , the ratio $k^{\prime} / k$ calculated by equations (10) and (11) is shown in Figure 2. $H$ is the depth of an elastic layer. It can be seen that the ratio of the foundation coefficient obtained by the two calculation methods approaches one as the Poisson ratio decreases. The Poisson ratio of the frozen soil decreases as the temperature decreases [23], indicating that the frozen soil coefficient calculation method obtained in this study is in accordance with the engineering reality.

2.4.2. Foundation Shear Stiffness G. There are many methods to determine the shear stiffness $(G)$ of the foundation, but the results are different. For example, Tanahashi [26], Song et al. [31], and $\mathrm{Li}$ [32] used the following formula to calculate the shear stiffness of the foundation:

$$
G=\frac{E_{f} t}{6(1+\mu)},
$$

where $t$ is the thickness of the shear layer.

It can be seen that with the difference in the thickness of the shear layer, the variation range of the foundation shear stiffness is very large. In actual engineering, the thickness of the shear layer is related to various factors such as soil physical properties, beam properties and dimensions, external load characteristics, and so on. Therefore, a constant foundation shear stiffness is unable to be selected [33]. To facilitate calculation and analysis, $\mathrm{Ma}$ et al. [34] determined simply the relationship between the foundation stiffness coefficient and the foundation coefficient by the following formula:

$$
R=\frac{G}{k}
$$

When $R$ is 0 , the model degenerates into a Winkler elastic foundation beam model.

\section{Parameters Analysis}

It can be seen from equations (2) and (3) that the internal force of the lining is affected by the foundation coefficient $k$, the shear modulus $G(R)$, the transition length $l$, and the frost heave displacement $\Delta$. This section will analyze and discuss 


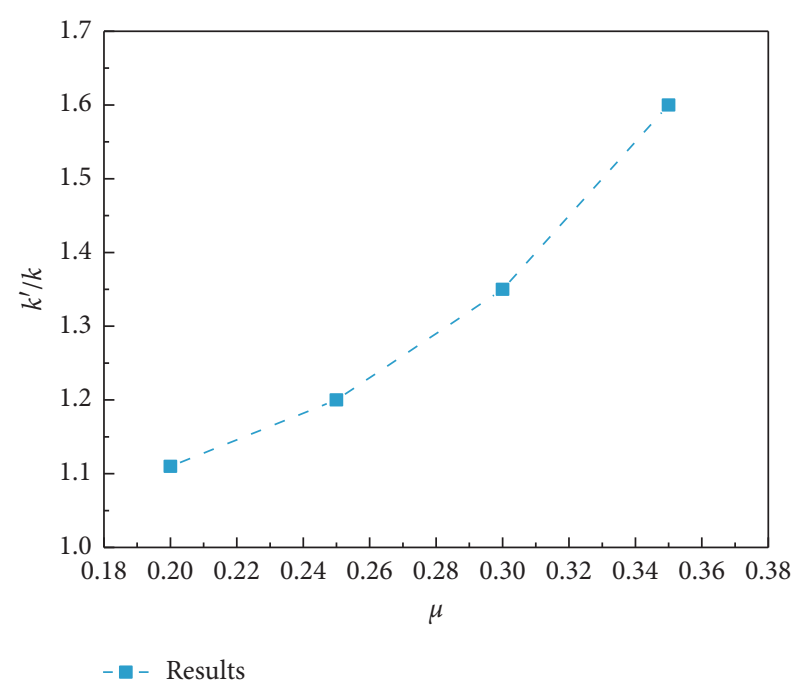

Figure 2: Values of $k ı / k$ for different Poisson ratios.

the internal force of the lining under the effects of the abovementioned parameters.

3.1. Effects of Foundation Coefficient $k$. It can be seen from formula (10) that when considering the interaction between frost heave deformation and frost heave force of the bottom lining, the foundation coefficient is related to the elastic modulus and the depth of frozen penetration. In the following parameter analysis, the typical frozen depth in Xinjiang, China, can be selected as $2 \mathrm{~m}$ [35]. The elastic modulus of the frozen soil layer is closely related to the physical properties, moisture content, and temperature of the soil mass [23]. Because the coarse-grained soil is frost heaving insensitive soil, the main cause of frost heaving deformation is silty clay. According to the data of Wang et al. [36] and the water transferring project from the Irtysh River to Urumqi, the selected foundation coefficients are $2.5 \times 103,13.8 \times 103$, $33 \times 103,45 \times 103$, and $58 \times 103 \mathrm{kN} \cdot \mathrm{m}^{-3}$ for analysis. Other relevant parameters are $E I=E b h 3 \cdot 12^{-1}=58666 \mathrm{kN} \cdot \mathrm{m}^{2}$, $b=4 \mathrm{~m}, h=0.2 \mathrm{~m}, E=2.2 \times 106 \mathrm{kPa}, R=1, l=10 \mathrm{~m}$, and $\Delta=0.02 \mathrm{~m}$. The maximum normal stress on the cross-section is calculated by $\sigma_{\max }=M y_{\max } / I$, and the maximum shear stress on the cross-section of the lining slab is calculated by $\tau_{\max }=3 Q_{s} / 2 A$. The calculation results are shown in Figures 3-5.

Figure 3 shows the distribution of lining deflection and rotation angle along the longitudinal direction for different foundation coefficients. It can be seen from Figure 3(a) that the deflection of the lining completely coincides when foundation coefficients are different. At the beginning $(x=0)$ and endpoint $(x=10)$ of the transition section, the deflection did not suddenly become 0 but smoothly transitioned to 0 . The deflection in the frost heave section is $0.02 \mathrm{~m}$ consistent with the set boundary conditions. It can be seen from Figure 3(b) that the foundation coefficient has a certain effect on the rotation angle of the beam. With the increase of the foundation coefficient, the changing trend of the rotation angle is more intense. At the midpoint of the transitional section $(x=5)$, the rotation angle is 0 . At the same time, Figure 3 shows that the deflection and rotation angle of the lining are in line with the actual engineering experience, and the calculation method and process in the previous section are verified to be correct.

Figure 4 shows the distribution laws of the maximum normal stress and the maximum shear stress of the lining slab along the longitudinal direction at different foundation coefficients. From the figure, the dangerous points where the maximum stress is located is at the beginning and the endpoint of the transition. With different foundation coefficients, the maximum normal stress and maximum shear stress at the attachment of the dangerous points change intensely, and the change at other positions is relatively slow.

Figure 5 shows the variation law of the maximum normal stress and maximum shear stress of the dangerous section of the bottom lining with the changing foundation coefficient. It can be seen that as the foundation coefficient increases, the maximum normal stress and the maximum shear stress increase nonlinearly, and the growth rate gradually decreases, satisfying the power function relationship.

3.2. Effects of Shear Stiffness G. The change in shear stiffness reflects the interaction between the spring elements of the soil mass. At the same time, it can reflect the continuity of foundation deformation to a certain extent [25]. According to formula (13), the change in shear stiffness can be expressed by the coefficient $R$. In this section, $R=1,0.8,0.5$, 0.01 , and 0 are used for analysis. When $R$ is 0 , the model degenerates into the Winkler model. Other parameters are $k=33000 \mathrm{kN} \cdot \mathrm{m}^{-3}, l=10 \mathrm{~m}$, and $\Delta=0.02 \mathrm{~m}$. Figure 6 shows the distribution situation of deflection and rotation angle of the bottom lining at different values of $R$. It can be seen that as the $R$ decreases, the maximum normal stress and shear stress at the beginning and endpoint of the transition section increase because the load on the shear layer decreases lead to the lining bears more load.

Figure 7 shows the variation law of maximum normal stress and shear stress of dangerous section of bottom lining with different $R$ values. It can be seen that as the $R$ value increases, the two stresses significantly decrease, the maximum normal stress decreases by $24.4 \%$, and the maximum shear stress decreases by $37.2 \%$, indicating that the shear resistance of frozen soil ground has a significant impact on the stress distribution characteristics of the lining. The frost heave amount increases continuously while the temperature decreases, while the shear stiffness of the foundation will also increase with it. The former increases the lining stress, while the latter reduces the lining stress, so the internal force of the lining changes couple mutually with them during the frost heave process.

3.3. Effects of Different Transition Length $l$. Due to the differences in geological conditions including water, heat, and load during construction and operation, the frost heave characteristics of the canal foundation soil at different positions in the longitudinal direction are different, causing the 


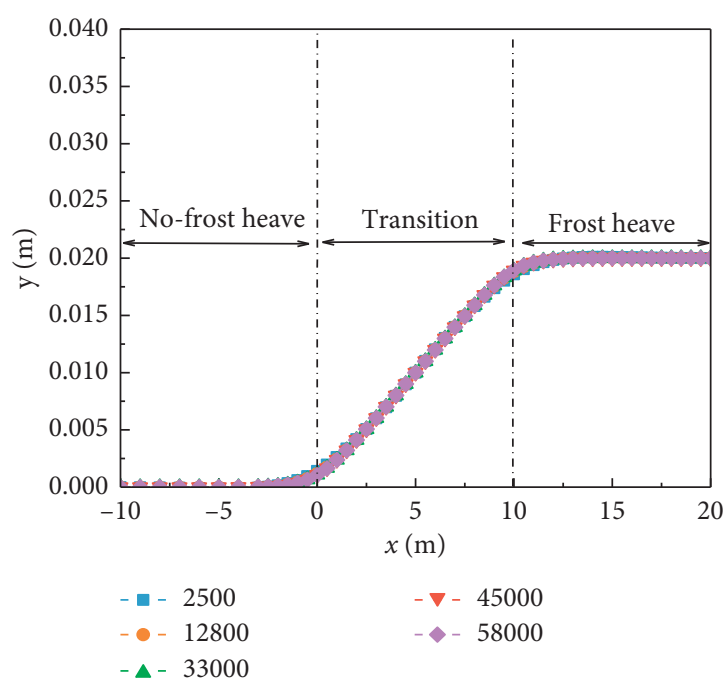

(a)

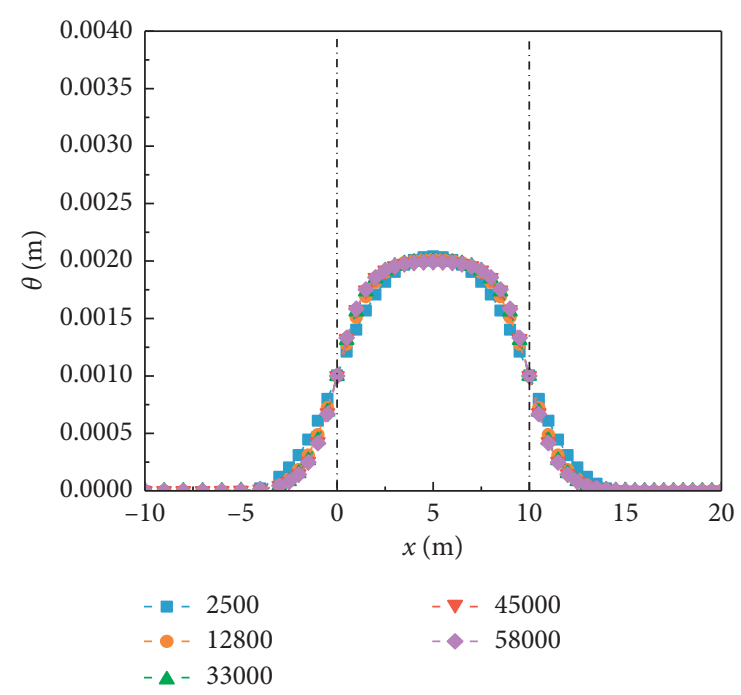

(b)

Figure 3: Effects of different foundation coefficients on the distribution of lining deflection (a) and rotation angle (b).

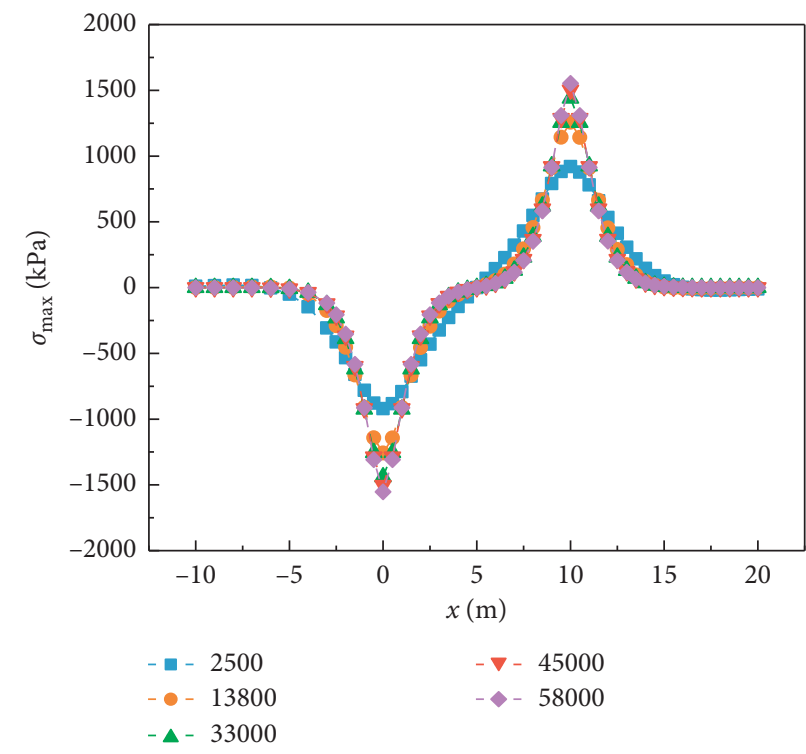

(a)

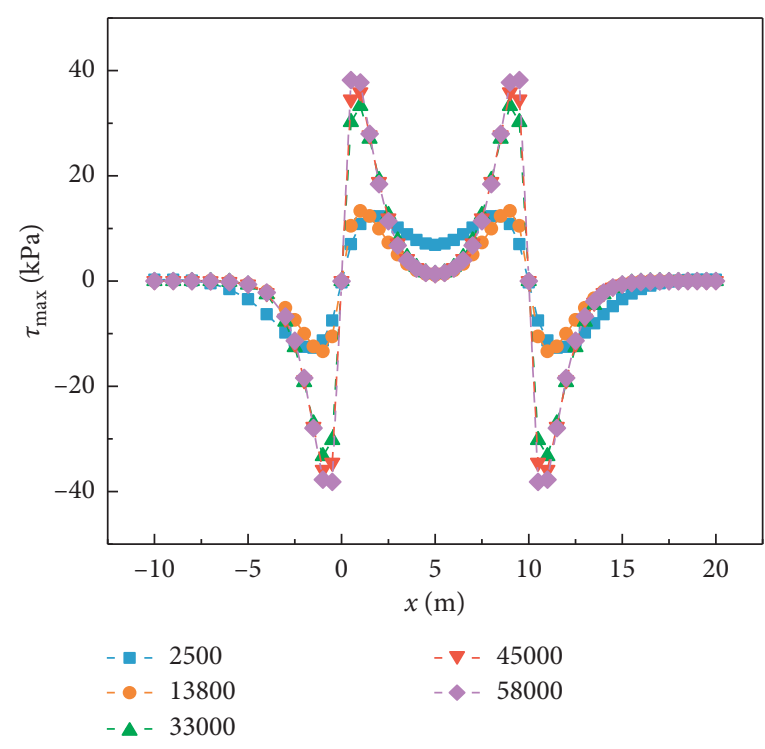

(b)

Figure 4: Distribution law of maximum normal stress (a) and maximum shear stress (b) of bottom lining under different foundation coefficients.

transition section length to change. In this section, the transition section length is $5,10,15$, and $20 \mathrm{~m}$ for analysis. Other parameters are $k=33000 \mathrm{kN} \cdot \mathrm{m}^{-3}, \quad R=1$, and $\Delta=0.02 \mathrm{~m}$.

Figure 8 shows the distribution law of the maximum normal stress and the maximum shear stress of the bottom lining cross-section at different transition lengths. It can be seen that as the transition section length increases, the maximum normal stress and shear stress of the dangerous section decrease, which is in line with the actual engineering situation.
Figure 9 shows the effect of different transition section lengths on the maximum normal stress and shear stress of the dangerous section. It can be seen that as the transition section length increases, the maximum stress and shear stress decrease significantly and change nonlinearly.

3.4. Effects of Different Frost Heave Amount $\Delta$. The canals in the cold regions will inevitably face the frost heaving issues. Different soil properties, temperature, and moisture conditions cause different frost heave amounts. It is pointed out 


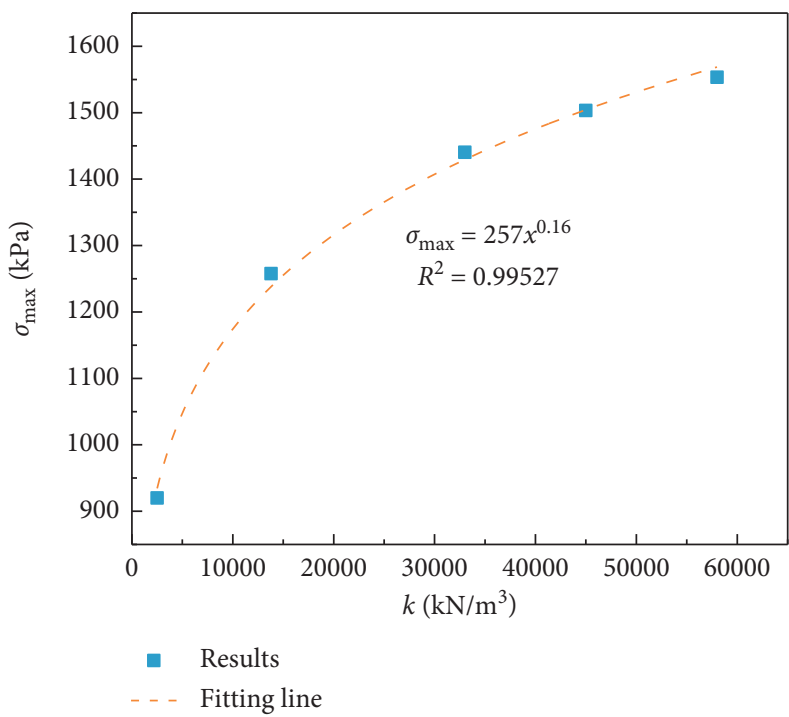

(a)

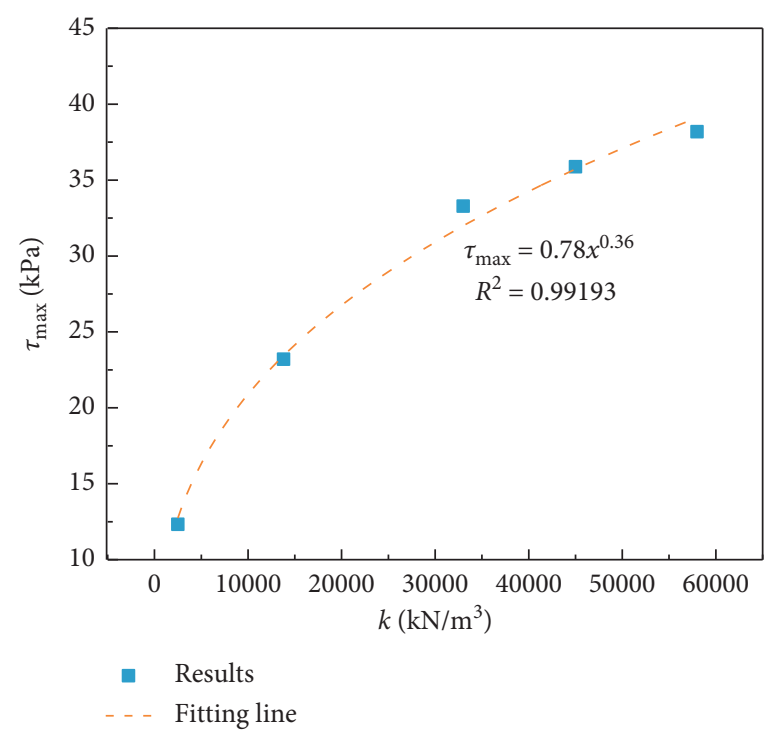

(b)

Figure 5: Variation law of maximum normal stress (a) and maximum shear stress (b) of the dangerous section with the changing foundation coefficients.

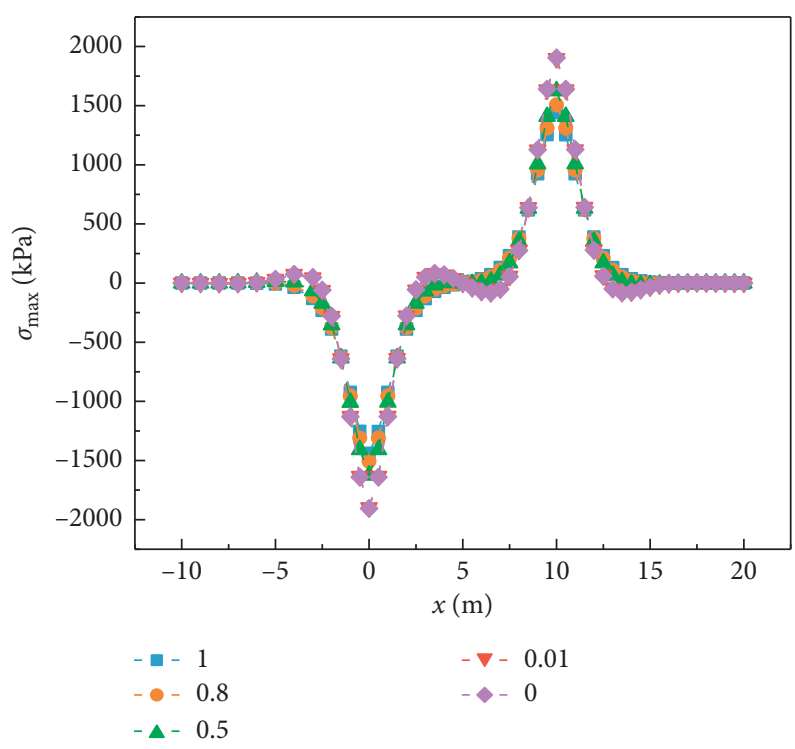

(a)

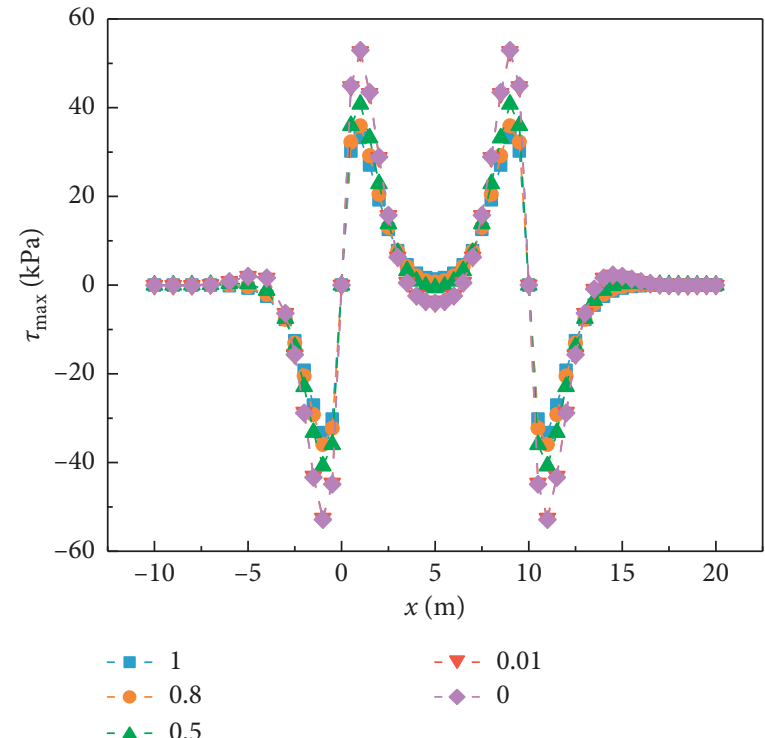

(b)

FIGURE 6: Distribution situation of maximum normal stress (a) and maximum shear stress (b) of bottom lining at different $R$ values.

in the standard designing specification for antifrost heaving of the canal project that the concrete lining can be allowed to generate a certain amount of frost heave displacement during the canal construction, and the purpose of reducing frost heave force and costs has achieved [37]. However, in the actual construction and operation process, due to the inevitable leakage and possible external water supply, the frost heave of the foundation soil of the canal may exceed the allowed design value, causing damage to the lining. In this section, $0.01,0.02,0.04,0.06$, and $0.08 \mathrm{~m}$ of frost heave amounts are selected for analysis. Other parameters are $k=33000 \mathrm{kN} \cdot \mathrm{m}^{-3}, R=1$, and $l=20 \mathrm{~m}$.

Figure 10 shows the maximum normal stress and shear stress of the lining cross-section under different frost heave amounts. It can be seen that the frost heave amount has a significant effect on the stress of the dangerous section.

Figure 11 shows the effect of different frost heave amounts on the maximum normal stress and shear stress of the dangerous section. It can be seen that the maximum normal stress and shear stress increase linearly with the 


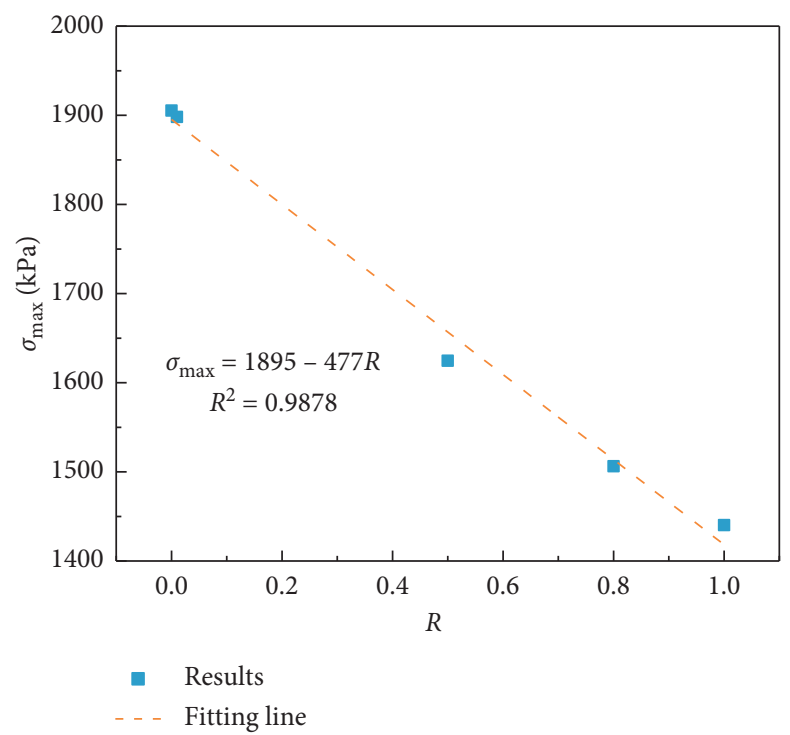

(a)

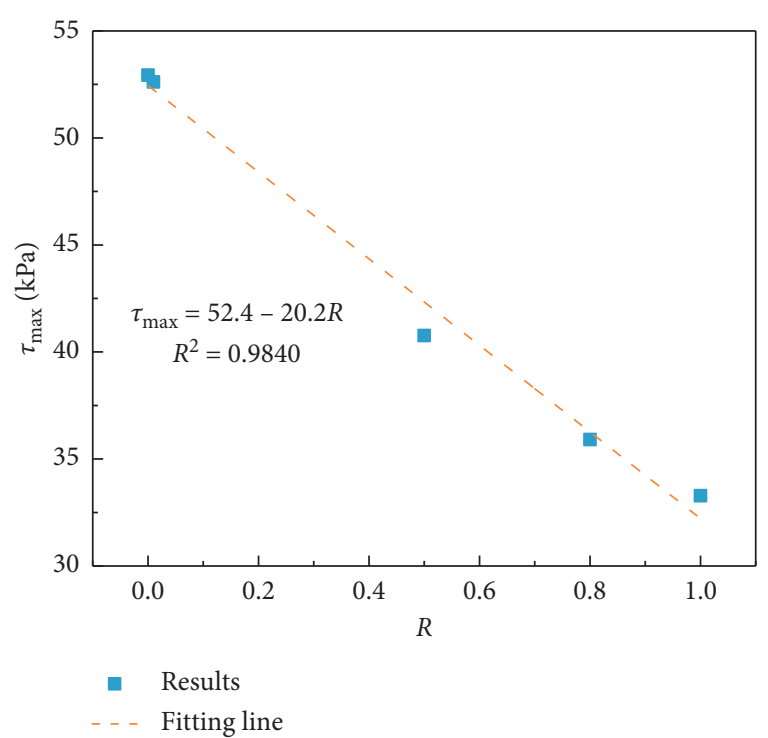

(b)

Figure 7: Effects of different $R$ values on the maximum normal stress (a) and maximum shear stress (b) of the dangerous section.

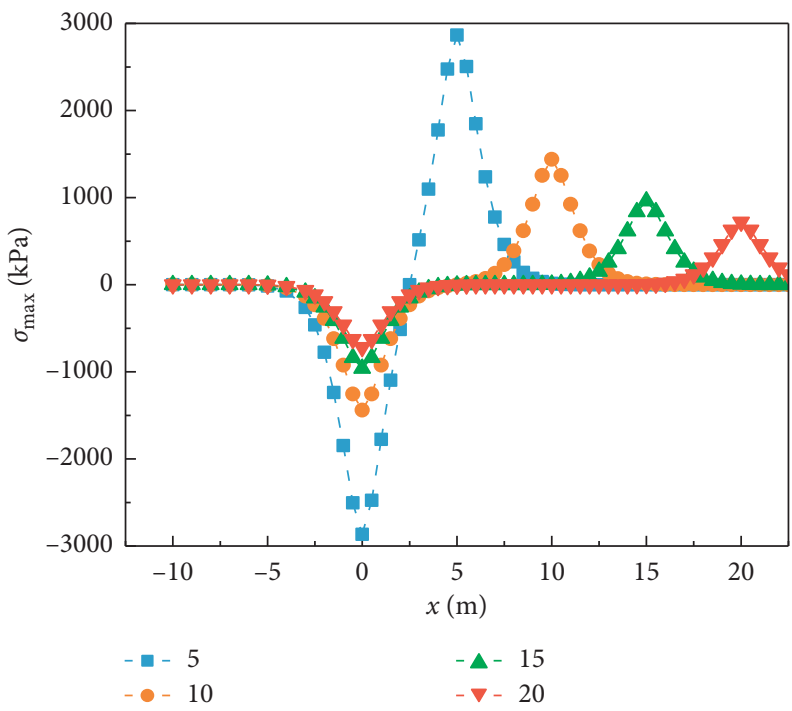

(a)

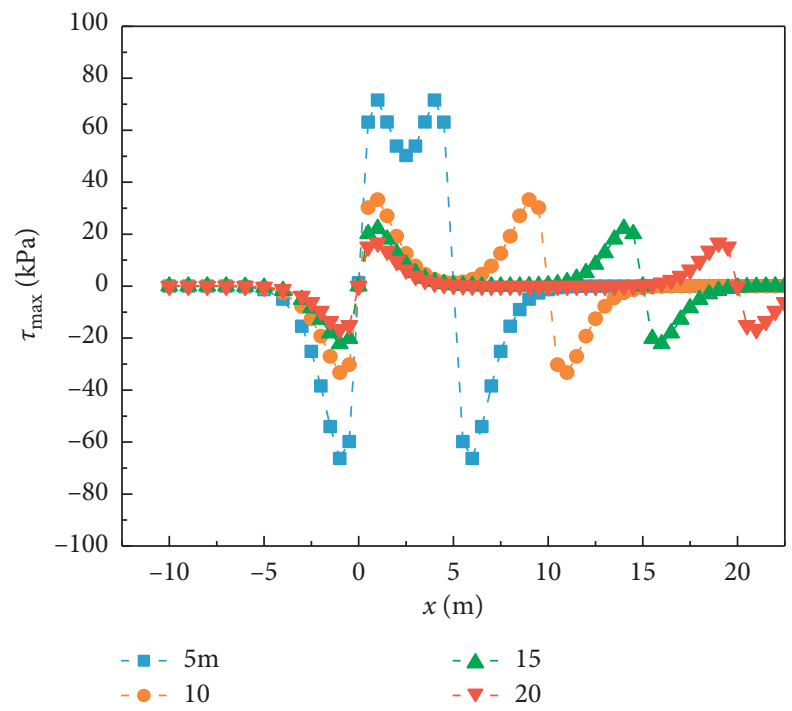

(b)

Figure 8: Distribution law of maximum normal stress (a) and maximum shear stress (b) of the cross-section at different transition section lengths.

increase of frost heave amount. When the frost heave amount is 0 , the maximum stress is also 0 .

\section{Engineering Case}

In the Tarim irrigation district of Xinjiang, more than $2355 \mathrm{~km}$ of canals have been constructed. Due to the abundant surface water and relatively shallow embedment depth, the canal lining has severe frost heave failure [10]. The typical cast-in-place canal lining is concrete lining (C15), with a slab thickness of $0.08 \mathrm{~m}$ and a bottom width of $2 \mathrm{~m}$. The minimum temperature of the frozen soil layer on the slope and the canal's bottom in winter is $-14.7^{\circ} \mathrm{C}$ and $-9.4^{\circ} \mathrm{C}$, respectively. The elastic modulus of the frozen soil layer takes the value of the minimum temperature in winter, which is safe, and the frozen depth of the canal is about $1 \mathrm{~m}$. According to site observations, the maximum frost heave displacement at the bottom canal is $0.022 \mathrm{~m}$. However, as the groundwater level changes, the maximum frost heave displacement may increase. According to estimates, when the 


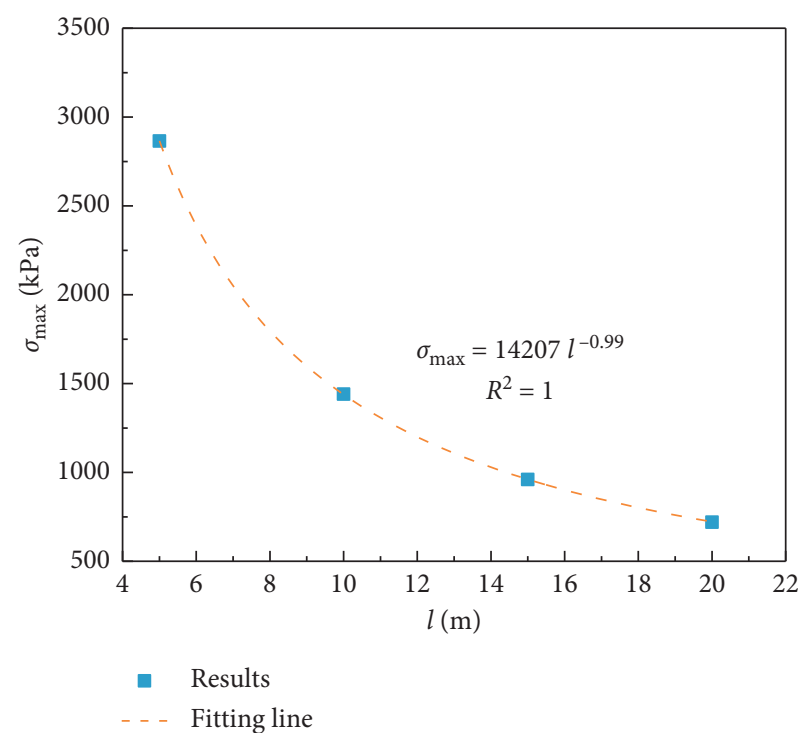

(a)

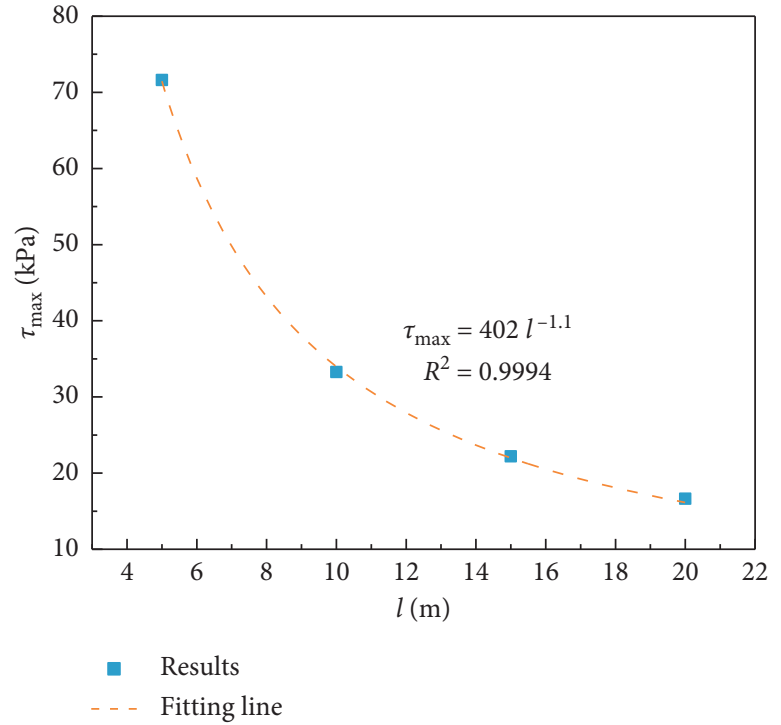

(b)

FIGURE 9: Effects of different transition lengths on the maximum normal stress (a) and maximum shear stress (b) of the dangerous section.

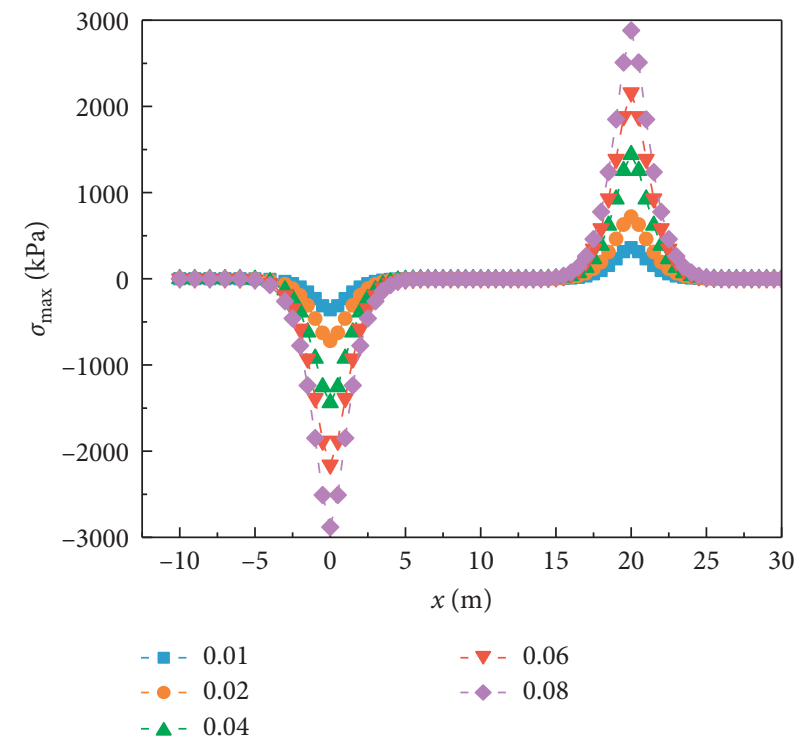

(a)

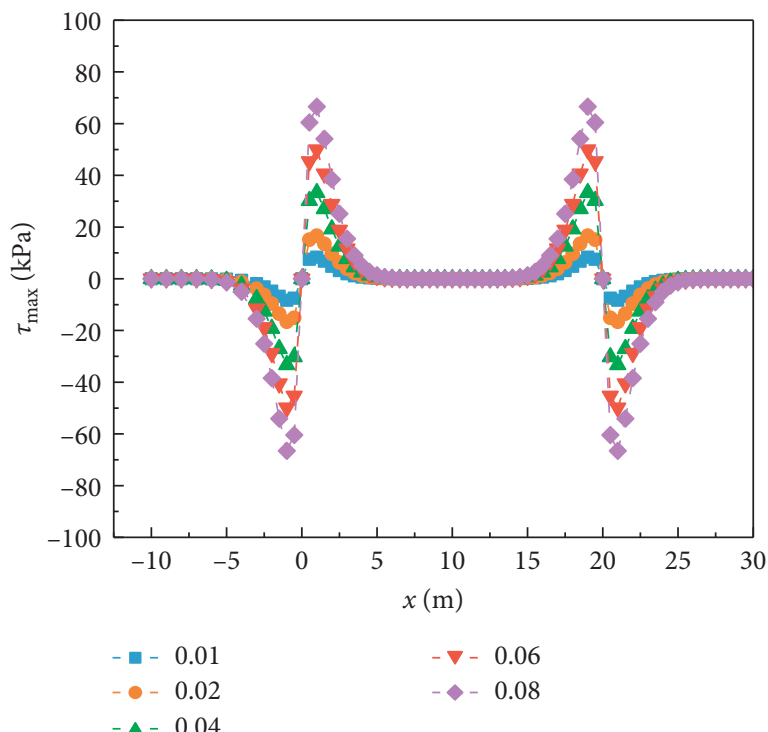

(b)

Figure 10: Distribution law of maximum normal stress and maximum shear stress of the lining cross-section under different frost heave amounts.

groundwater level is $3.0,3.5,4.0,4.5$, and $5.0 \mathrm{~m}$, the maximum frost heave amounts are $0.031,0.022,0.015,0.01$, and $0.005 \mathrm{~m}$, respectively [10].

Xiao et al. [10, 38] monitored and calculated the horizontal deformation of the lining, but the longitudinal deformation caused by nonuniform frost heave has not been studied. Therefore, the longitudinal deformation is analyzed according to the calculation method in this study. The selected parameters are $E=2.2 \times 104 \mathrm{MPa}, E_{f}=2.35 \mathrm{MPa}$, $k=2.35 \mathrm{MPa} \cdot \mathrm{m}^{-1}, R=1, G=2.35 \mathrm{MPa} \cdot \mathrm{m}, E I=1.877 \mathrm{MPa}$, and $l=10 \mathrm{~m}$.
Figure 12 shows the effect of different frost heave amounts on the maximum normal stress and shear stress of the dangerous section of the lining. It can be seen that with the increase of frost heave amounts, the maximum normal stress and shear stress of the dangerous section increase linearly, and the growth speed at the transition section of $5 \mathrm{~m}$ is greater than that at the transition section of $10 \mathrm{~m}$. The maximum tensile stress of $\mathrm{C} 15$ concrete lining is $1.27 \times 103 \mathrm{kPa}$ [39], and the designing tensile stress is $0.91 \times 103 \mathrm{kPa}$. Therefore, when the transition section is $5 \mathrm{~m}$ and the frost heave amount reach $0.022 \mathrm{~m}$, the lining is about 


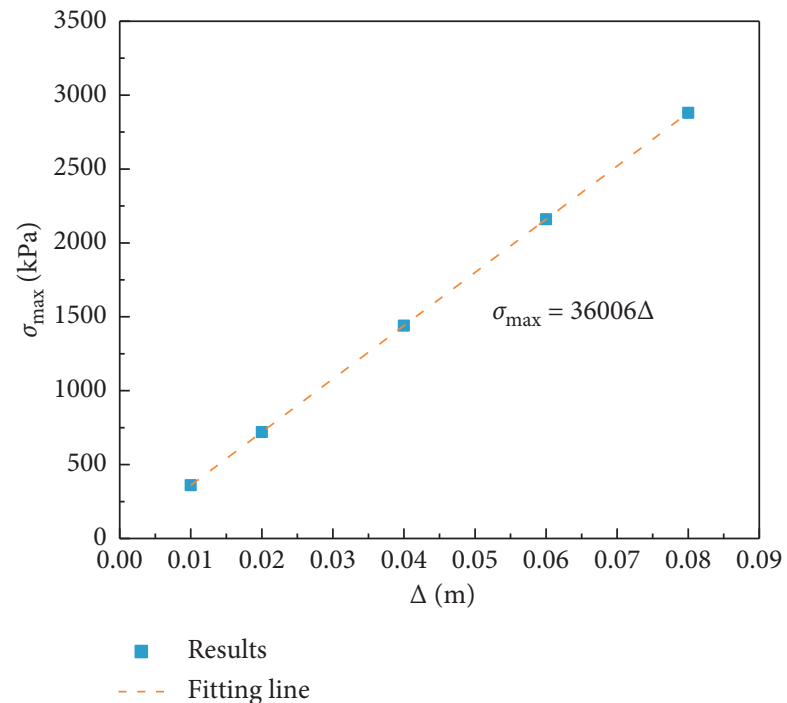

(a)

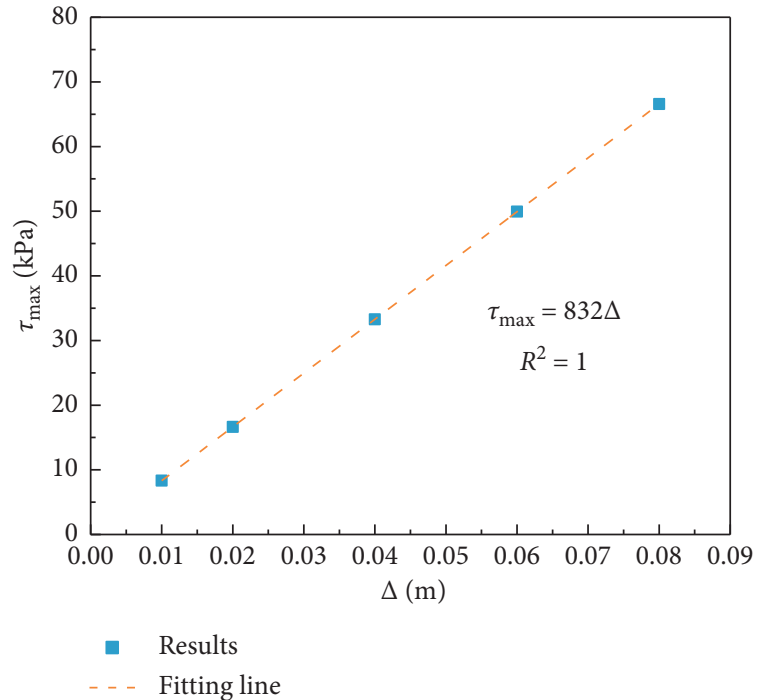

(b)

Figure 11: Effects of different frost heave amounts on maximum normal stress (a) and maximum shear stress (b).

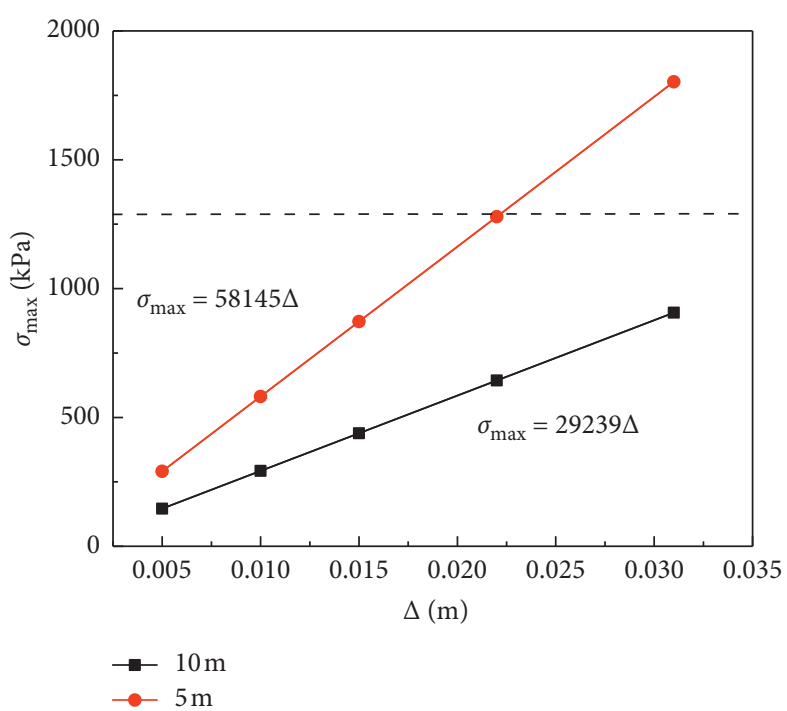

(a)

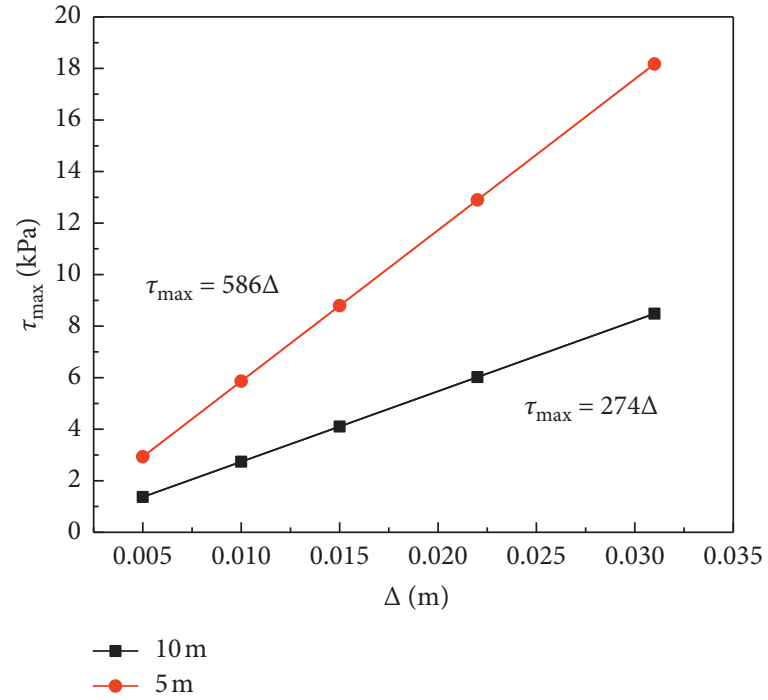

(b)

Figure 12: Effects of different frost heave amounts on the maximum normal stress (a) and maximum shear stress (b) of the dangerous section.

to at the limit state, which is close to the maximum allowable frost heave amount for designing specification. When the transition section is $10 \mathrm{~m}$ and the frost heave amount reach $0.043 \mathrm{~m}$, the lining is at the limit state, which is greater than the maximum allowable frost heave amount for designing specification. The maximum shear stress of the cross-section is far less than the ultimate shear strength and is in a safe state.
Figure 13 shows the effect of different transition lengths on the maximum normal stress and shear stress of the dangerous section when the frost heave amount $\Delta=0.031 \mathrm{~m}$. It can be seen that as the transition section length increases, the maximum normal stress and shear stress decrease significantly. When the transition section length is $7 \mathrm{~m}$, the maximum normal stress is lower than the ultimate tensile stress of the lining. When the transition section length is 


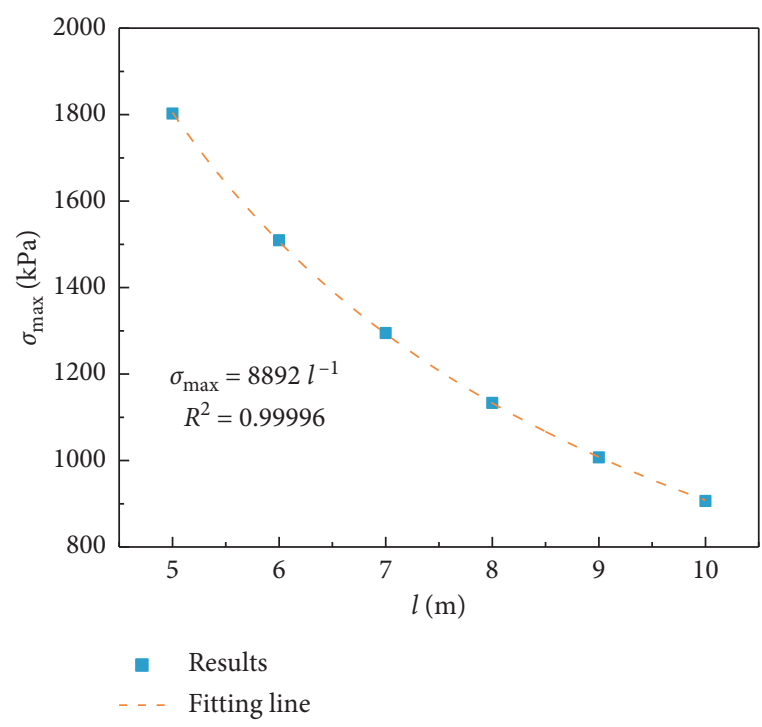

(a)

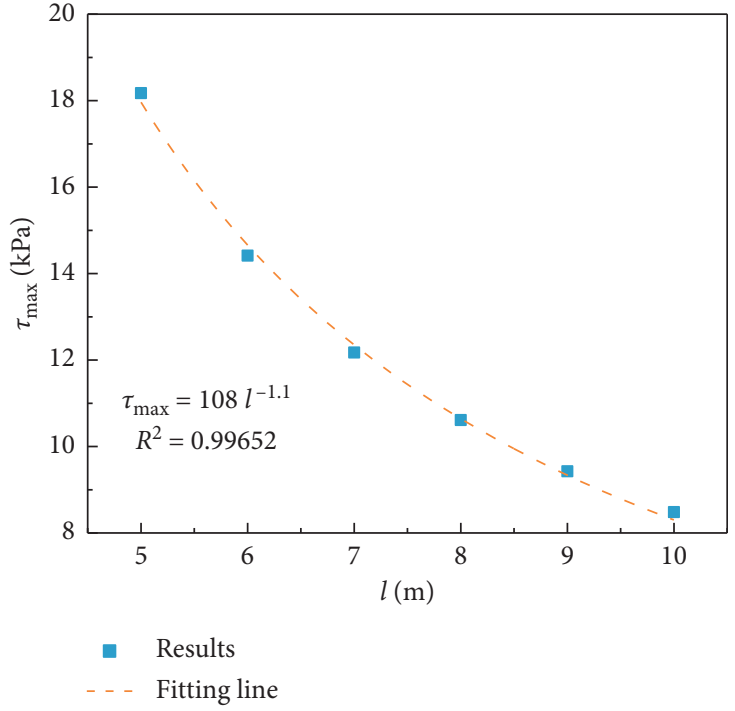

(b)

FiguRE 13: Effects of different transition lengths on the maximum normal stress (a) and maximum shear stress (b) of the dangerous section when the frost heave amount $\Delta=0.031 \mathrm{~m}$.

$9.8 \mathrm{~m}$, the maximum normal stress is lower than the designing tensile stress of the lining. Therefore, it is recommended to design expansion joints with a longitudinal separation of at least $7 \mathrm{~m}$ in the canal design process to relieve the internal stress of the lining.

\section{Conclusion}

To analyze the longitudinal mechanical characteristics of the canal lining in the cold regions under nonuniform frost heave, based on the Pasternak elastic foundation beam model, the longitudinal deformation model of the bottom lining is established. The changing law of the maximum tensile stress and shear stress in the lining are analyzed when the key parameters $k, G, L$, and $\Delta$ change in the model. Finally, in conjunction with engineering example, the effects of frost heave amounts and transition section lengths on the safety of a typical canal lining in the Tarim irrigation area in Xinjiang are analyzed. The following conclusions are obtained:

(1) Due to the low bending rigidity of the concrete lining, the bottom lining along the longitudinal direction is simplified. The longitudinal lining is regarded as a beam, and the force acting on the lining is simplified. The Pasternak elastic foundation beam model of the bottom lining under the action of longitudinal nonuniform frost heave is established, and the analytical solution of the model is given.

(2) Calculate the influence of factors such as foundation coefficient, foundation shear modulus, transition section length, and frost heave amount on the internal force of the lining. The dangerous section of the lining is at the beginning and endpoint of the transition section. The maximum normal stress and shear stress of the dangerous section increase as the foundation coefficient and frost heave amount increase and the shear modulus and transition section length decrease.

(3) The frost heave amount continuously increases while the temperature of frozen soil foundation decreases, but the shear stiffness of the foundation will also increase with it. The former increases the lining stress, while the latter reduces it, so during the frost heave process, the internal force of lining changes are coupled with them.

(4) Through the analysis of the longitudinal deformation of the lining of a water delivery canal under nonuniform frost heave action in the Tarim irrigation district of Xinjiang, when the local maximum frost heave amount is $0.031 \mathrm{~m}$ and the transition section length is less than $7 \mathrm{~m}$, the maximum normal stress of the dangerous lining section is greater than its maximum tensile strength. Thus, it is recommended to set expansion joints with a separation of at least $7 \mathrm{~m}$ on the floor lining of this section of the channel.

Because it is relatively difficult to monitor the longitudinal frost heave deformation of the lining, the calculation results in this study cannot be verified by experimental data at present. However, the comparison with the actual engineering phenomenon shows that the analytical solution is correct. In the follow-up work, on-site monitoring of longitudinal deformation and indoor model tests will be carried out to further study the model.

\section{Data Availability}

The data used to support the findings of this study are included within the article. 


\section{Conflicts of Interest}

The authors declare that they have no conflicts of interest.

\section{Acknowledgments}

This work was supported by the National Natural Science Foundation of China (42001058 and 51778275) and Longyuan Young Innovative and Entrepreneurial Talents (2020RCXM120).

\section{References}

[1] Y. Zhou, D. Guo, G. Qiu, G. Chen, and S. Shu, Geocryology in China, Science Press, Beijing, China, 2000.

[2] O. B. Andersland and B. Landanyi, Frozen Ground Engineering, John Wiley \& Sons, Inc. and ASCE American Society of Civil Engineering, Hoboken, NJ, USA, 2nd edition, 2004.

[3] S. Zhang, Z. Pu, J. Li et al., "Response of the maximum depth of seasonal freezing to the cumulated negative temperature on Xingjiang," Journal of Glaciology and Geocryology, vol. 35, no. 6, pp. 1419-1427, 2013.

[4] Z. Qin, Y. Lai, Y. Tian, and F. Yu, "Frost-heaving mechanical model for concrete face slabs of earthen dams in cold regions," Cold Regions Science and Technology, vol. 161, pp. 91-98, 2019.

[5] Z. Cai, H. Chen, Y. Huang, and C. Zhang, "Failure mechanism of canal slopes of expansive soils considering action of wetting-drying cycles," Chinese Journal of Geotechnical Engineering, vol. 41, no. 11, pp. 1977-1982, 2018.

[6] A. Zia and M. Ali, "Behavior of fiber reinforced concrete for controlling the rate of cracking in canal-lining," Construction and Building Materials, vol. 155, pp. 726-739, 2017.

[7] P. He and W. Ma, "Study of canals in cold regions of China: achievements and prospects," Journal of Glaciology and Geocryology, vol. 42, no. 1, pp. 182-194, 2020.

[8] Q. Miao, F. Niu, Z. Lin, J. Luo, and M. Liu, "Comparing frost heave characteristics in cut and embankment sections along a high-speed railway in seasonally frozen ground of Northeast China," Cold Regions Science and Technology, vol. 170, Article ID 102921, 2020.

[9] R. Zhang and Z. Wang, "The progress of the research on the prevention and cure of the irrigation channel frozen injury in the seasonal frozen soil," Agricultural Research in Arid Areas, vol. 25, no. 3, pp. 236-240, 2007.

[10] M. Xiao, Z. Wang, Q. Liu, Y. Wang, J. Ge, and X. Wang, "Elastic foundation beam model of frost heave damage of trapezoidal canal considering interaction between frozen soil and lining structure," Shuli Xuebao, vol. 48, no. 10, pp. 1229-1239, 2017.

[11] J. Sun, G. Li, Q. Zhang, and H. Zhang, "Stability analysis of earth-rock dam slope on the action of ice cover," Journal of Heilongjiang Hydrology Engineering College, vol. 1, pp. 26-28, 1998.

[12] Y. Tian, Z. Yang, B. Tai, Y. Li, and Y. Sheng, "Damage and mitigation of railway embankment drainage trench in warm permafrost: a case study," Engineering Geology, vol. 261, Article ID 105276, 2019.

[13] K. Hirayama, Thrust on Hydraulic Structures Due to the Thermal Expansion of Ice Cover, Vol. 9, Technology Rep Iwate University, Morioka, Japan, 1976.

[14] X. Liu, P. Liu, and H. Li, "Application of fracture mechanics to analyze frost breakage of reservoir revetments in cold regions," Journal of Glaciology Geocryology, vol. 32, no. 3, pp. $543-548,2010$.

[15] R. Sadzevicius, V. Damulevicius, and R. Skominas, "The technical state of earth dams in Lithuania," Journal of Environment Engineering Landsec Management, vol. 21, no. 3, pp. 180-188, 2013.

[16] P. An, Y. Xing, and A. Zhang, “Thickness calculation and numerical simulation of insulation board for canal using partial insulation method," Transaction of the CSAE, vol. 29, no. 17, pp. 54-62, 2013.

[17] S. Li, M. Zhang, Y. Tian, W. Pei, and H. Zhong, "Experimental and numerical investigations on frost damage mechanism of a canal in cold regions," Cold Regions Science and Technology, vol. 116, pp. 1-11, 2015.

[18] S. Li, Y. Lai, M. Zhang, W. Pei, C. Zhang, and F. Yu, "Centrifuge and numerical modeling of the frost heave mechanism of a cold-region canal," Acta Geotechnica, vol. 14, no. 4, pp. 1113-1128, 2019.

[19] Z. Wang, "Establishment and application of mechanics models of frost heaving damage of concrete lining trapezoidal open canal," Transaction of the CSAE, vol. 3, pp. 24-29, 2004.

[20] H. Jiang, Z. Wang, Y. Wang, Q. Liu, and J. Ge, "Study on antifrost heave mechanism and application of reasonable joint for large size trapezoidal canal with arc-bottom," Transaction of the CSAE, vol. 50, no. 8, pp. 947-959, 2019.

[21] J. Ge, Z. Wang, Y. Niu et al., "Elastic foundation beam unified model for ice and frost damage concrete canal of water delivery under ice cover," Transaction of the CSAE, vol. 36, no. 1, pp. 90-98, 2020.

[22] Z. Li, X. Yao, L. Yang, H. Shao, and Z. Wang, "Frost heave mechanical model of concrete lining trapezoidal canal based on elastic foundation beam theory," Transaction of the CSAE, vol. 35, no. 15, pp. 110-117, 2019.

[23] Z. Zhou, W. Ma, S. Zhang, Y. Mu, and G. Li, "Effect of freezethaw cycles in mechanical behaviors of frozen loess," Cold Regions Science and Technology, vol. 146, pp. 9-18, 2018.

[24] Z. Zhou, W. Ma, S. Zhang, Y. Mu, and G. Li, "Experimental investigation of the path-dependent strength and deformation behaviors of frozen loess," Engineering Geology, vol. 265, Article ID 105449, 2020.

[25] A. Selvadurai, Elastic Analysis of Soil-Foundation Interaction, Elsevier Scientific, Amsterdam, Netherlands, 1979.

[26] H. Tanahashi, "Formulas for an infinitely long Bernoulli-euler beam on the pasternak model," Soils and Foundations, vol. 44, no. 5, pp. 109-118, 2004.

[27] Z. Feng and R. Cook, "Beam elements on two-parameter elastic foundations," Journal of Engineering Mechanics, vol. 109, no. 6, pp. 1390-1402, 1983.

[28] S. Kanie, S. Akagawa, K. Kim, and T. Mikami, "Estimation method of frost heaving for chilled gas pipeline buried in frost susceptible soil," International Conference on Cold Regions Engineering, pp. 1-12, 2006.

[29] I. Coskun, H. Engin, and A. Ozmutlu, "Response of a finite beam on a tensionless Pasternak foundation under symmetric and asymmetric loading," Structural Engineering and $\mathrm{Me}$ chanics, vol. 30, no. 1, pp. 21-36, 2008.

[30] L. Huang, Y. Sheng, X. Hu, S. Wang, X. Huang, and B. He, "Stress analysis of pipelines subjected to frost heave based on the theory of elastic foundation beam," Journal of Glaciology and Geocryology, vol. 40, no. 1, pp. 70-78, 2018.

[31] G. Song, X. Bian, and J. Jiang, "Deformation behaviors and bearing capacity of geosynthetics-reinforced pavement," Journal of Shanghai Jiaotong University, vol. 45, no. 5, pp. 653-658, 2011. 
[32] F. Li, "Research on superposition method of interaction between soil frost heave and beams on foundation," Rock and Soil Mechanics, vol. 30, no. 1, pp. 79-85, 2009.

[33] Y. Liang, Y. Li, and M. Huang, "Simplified method for laterally loaded piles based on Pasternak double-parameter spring model for foundations," Chinese Journal of Geotechnical Engineering, vol. 35, pp. 300-304, z1, 2013.

[34] X. Ma, J. W. Butterworth, and G. C. Clifton, "Static analysis of an infinite beam resting on a tensionless Pasternak foundation," European Journal of Mechanics-A/Solids, vol. 28, no. 4, pp. 697-703, 2009.

[35] X. Xu, Physics of Frozen Soil, Science Press, Beijing, China, 2010.

[36] S. Wang, J. Qi, F. Yu, and X. Yao, "A novel method for estimating settlement of embankments in cold regions," Cold Regions Science and Technology, vol. 88, pp. 50-58, 2013.

[37] SL23-2006, Design Code for Anti-frost-heave of Canal and its Structure, China Water \& Power Press, Beijing, China, 2005.

[38] M. Xiao, Studies on Channel Damage Mechanism and Tis Prevention Measures in Tarim Irrigation, Tarim University, Xinjiang, China, 2011.

[39] GB 50010-2010, Code For Design of Concrete Structures, China Architecture \& Building Press, Beijing, China, 2015. 